\title{
Polymorphic genes of detoxification and mitochondrial enzymes and risk for progressive supranuclear palsy: a case control study
}

\author{
Lisa F Potts ${ }^{1}$, Alex C Cambon², Owen A Ross ${ }^{3}$, Rosa Rademakers ${ }^{3}$, Dennis W Dickson ${ }^{3}$, Ryan J Uitti ${ }^{4}$, \\ Zbigniew K Wszolek ${ }^{4}$, Shesh N Rai ${ }^{2,5}$, Matthew J Farrer ${ }^{3,6}$, David W Hein ${ }^{5,7}$ and Irene Litvan ${ }^{1,8,9^{*}}$
}

\begin{abstract}
Background: There are no known causes for progressive supranuclear palsy (PSP). The microtubule associated protein tau (MAPT) H1 haplotype is the major genetic factor associated with risk of PSP, with both oxidative stress and mitochondrial dysfunction also implicated. We investigated whether specific single nucleotide polymorphisms (SNPs) in genes encoding enzymes of xenobiotic detoxification, mitochondrial functioning, or oxidative stress response, including debrisoquine 4-hydroxylase, paraoxonase 1 and 2, N-acetyltransferase 1 and 2 (NAT2), superoxide dismutase 1 and 2, and PTEN-induced putative kinase are associated with PSP.

Methods: DNA from 553 autopsy-confirmed Caucasian PSP cases (266 females, 279 males; age at onset $68 \pm 8$ years; age at death $75 \pm 8$ ) from the Society for PSP Brain Bank and 425 clinical control samples (197 females, 226 males; age at draw $72 \pm 11$ years) from healthy volunteers were genotyped using Taqman PCR and the SequenomiPLEX Gold assay.

Results: The proportion of NAT2 rapid acetylators compared to intermediate and slow acetylators was larger in cases than in controls $(\mathrm{OR}=1.82, \mathrm{p}<0.05)$. There were no allelic or genotypic associations with PSP for any other SNPs tested with the exception of MAPT $(p<0.001)$.

Conclusions: Our results show that NAT2 rapid acetylator phenotype is associated with PSP, suggesting that NAT2 may be responsible for activation of a xenobiotic whose metabolite is neurotoxic. Although our results need to be further confirmed in an independent sample, NAT2 acetylation status should be considered in future genetic and epidemiological studies of PSP.
\end{abstract}

Keywords: Progressive supranuclear palsy (PSP), N-acetyltransferase 2 (NAT2), Tauopathy, Single nucleotide polymorphisms (SNPs), Parkinson?'?s disease (PD)

\section{Background}

Progressive supranuclear palsy (PSP) is the most common atypical parkinsonian disorder. Classically, patients present with progressive postural instability and falls followed by slow and hypometric vertical saccades and eventually vertical supranuclear gaze palsy.

Neuropathologically, PSP is characterized by deposits of four-repeat microtubule associated protein tau (encoded by the MAPT gene) aggregates in neurons and

\footnotetext{
* Correspondence: ilitvan@ucsd.edu

'Department of Anatomical Sciences and Neurobiology, University of Louisville, Louisville, KY, USA

Full list of author information is available at the end of the article
}

glia of the basal ganglia and brain-stem [1]. Additionally, there is mitochondrial dysfunction, decreased ATP levels and inflammation in the brains of PSP patients [2-4]. The MAPT $\mathrm{H} 1$ haplotype has been consistently reported to be associated with PSP; however, it is also common in the general population, suggesting that gene-gene or gene-environment interactions are likely required for the development of this disease [5,6]. Recently, MAPT $H 1$ was also associated with risk of Parkinson's disease (PD) suggesting shared pathways of disease [7]. Earlyonset PD and PSP can present with a similar phenotype and be misdiagnosed, supporting common links between the two disorders. The product of PTEN-induced

\section{Biomed Central}


putative kinase (PINK1, PARK6), associated with earlyonset $\mathrm{PD}$, is involved in mitochondrial respiration and protection from oxidative damage, which are pathways that have also been linked to risk of PSP [8-13]. PINK-1 polymorphisms are also associated with $\mathrm{PD}$ and it acts in conjunction with parkin to regulate mitochondrial functioning. Although the mechanisms by which PINK1 acts are not fully understood; research suggests that it is crucial for healthy mitochondrial respiration and ATP production [8]. Considering the role of PINK1 in mitochondrial functioning along with its previous links to PD, specific PINK1 SNPs were included in this study to determine if there is also an association with PSP.

Consumption of annonaceous fruit and teas, which contain mitochondrial inhibitors, has been associated with an atypical parkinsonian disorder similar to PSP in the French West Indies $[14,15]$. Considering that mitochondrial impairment is observed in PSP brains, mitochondrial complex-1 inhibitors and other chemical neurotoxins, such as organophosphates, are hypothesized as risk factors for PSP [16-18]. These and other potentially toxic compounds are metabolized by the products of several genes: debrisoquine 4-hydroxylase (CYP2D6), paraoxonase (PON) 1 and 2, N-acetyltransferase (NAT) 1 and 2, and superoxide dismutase (SOD) 1 and $2[10-13,19-22]$. CYP2D6 is found in the brain and is involved in metabolism of MPTP, herbicides (paraquat) and organophosphate pesticides [11,12]. Reduced in $5-10 \%$ of Caucasians, genetic polymorphisms of this enzyme have been widely studied in PD and results suggest that there is an association of the poor metabolizer phenotype with disease development [23,24]. Moreover, the combination of pesticide exposure and CYP2D6 poor metabolizer phenotype doubles PD risk $[11,20]$. PON1 hydrolyzes phosphoric acid esters, organophosphates and aromatic carboxylic acid esters and blocks the formation of free radicals. With low PON1 activity, these pesticides are not metabolized and the cell is subject to increased oxidative stress [19]. The PON $1 \mathrm{M}$ allele, which is correlated with decreased protein levels, has been shown to be associated with PD $[25,26]$ and the $\mathrm{M} / \mathrm{M}$ genotype was recently reported to be associated with early onset PD [27]. Additionally, decreased PON1 activity was overrepresented in PD patients from agriculturally exposed areas [19]. NAT1 and NAT2 are involved in the biotransformation of drugs and environmental toxins (xenobiotics) [28]. These enzymes transfer the acetyl group from acetyl-coenzyme A (acetyl CoA) to an amino group on aromatic amines and hydrazine compounds. In addition, following $\mathrm{N}$-hydroxylation, they can further activate xenobiotics via O-acetylation [29]. There are a number of SNPs reported in NAT1 and NAT2, which lead to slow and rapid acetylator phenotypes. The acetylation status of an individual might determine how they respond to xenobiotic exposures, therefore presenting the NAT genes as candidates for gene-environment interaction studies. The slow acetylator phenotype is reported to be associated with PD, but inconsistent results warrant further investigation [30-34]. SOD is an important antioxidant enzyme, which converts superoxide anions $\left(\mathrm{O}_{2^{-}}\right)$to hydrogen peroxide $\left(\mathrm{H}_{2} \mathrm{O}_{2}\right)$. Considering the antioxidant properties of the enzyme, polymorphisms resulting in decreased SOD activity would be expected to have detrimental effects on the cell; however, recent studies suggest the opposite is true [35-37]. The mechanism behind this gain of function toxicity remains unknown, but it is proposed to be a result of either 1) disrupting the balance of $\mathrm{O}_{2}$ - and $\mathrm{H}_{2} \mathrm{O}_{2}$, or 2) self-aggregation. Numerous SOD polymorphisms have been found to be associated with amyotrophic lateral sclerosis (ALS) [38], and may play a role in $\mathrm{PD}$ and AD pathogenesis [39].

To determine if genetic polymorphisms in toxicant metabolism increases risk for developing PSP, we investigated associations between PSP and specific single nucleotide polymorphisms (SNPs) in the aforementioned genes.

\section{Methods Sample}

DNA samples from 545 autopsy-confirmed PSP cases collected between 1993 and 2008 at the PSP Society Brain Bank were included [40]. All cases were from the US and Canada. Control DNA samples $(n=426)$ were randomly selected from an existing repository of control samples at the Mayo clinic, Jacksonville. All controls were healthy spouses or caregivers of patients at the Mayo Clinic in Jacksonville, FL and free from neurological disorders. All samples were from adults over the age of 33 (see Table 1 for demographic information). Institutional review board (IRB)-approved protocols, including informed consent, were followed to obtain all DNA samples.

\section{Genotyping}

Within 48 hours of collection, DNA was extracted by standard protocols and stored at $-80^{\circ} \mathrm{C}$ until used. NAT1 (rs4987076, rs5030839, rs4986782, rs1057123, and rs15561) and NAT2 (rs1208, rs1801279, rs1801280, rs1799929, rs1799930, rs1799931, and rs1041983) genotyping was performed using Taqman PCR methodology on an ABI Prism 7700 sequence detection system as previously published $[41,42]$. All other genotyping was performed on a Sequenom Mass Array iPLEX platform using the Gold Assay (San Diego, CA) as described previously [43] (see Table 2 for rs numbers). Primer sequences are available upon request. The rs numbers tested here also included in the recent GWAS on PSP are rs1043424, rs662, rs7493, rs1801280, rs1799930, rs1799931, rs1799929, and rs1041983 [44]. 
Table 1 Characteristics of PSP Cases and Controls

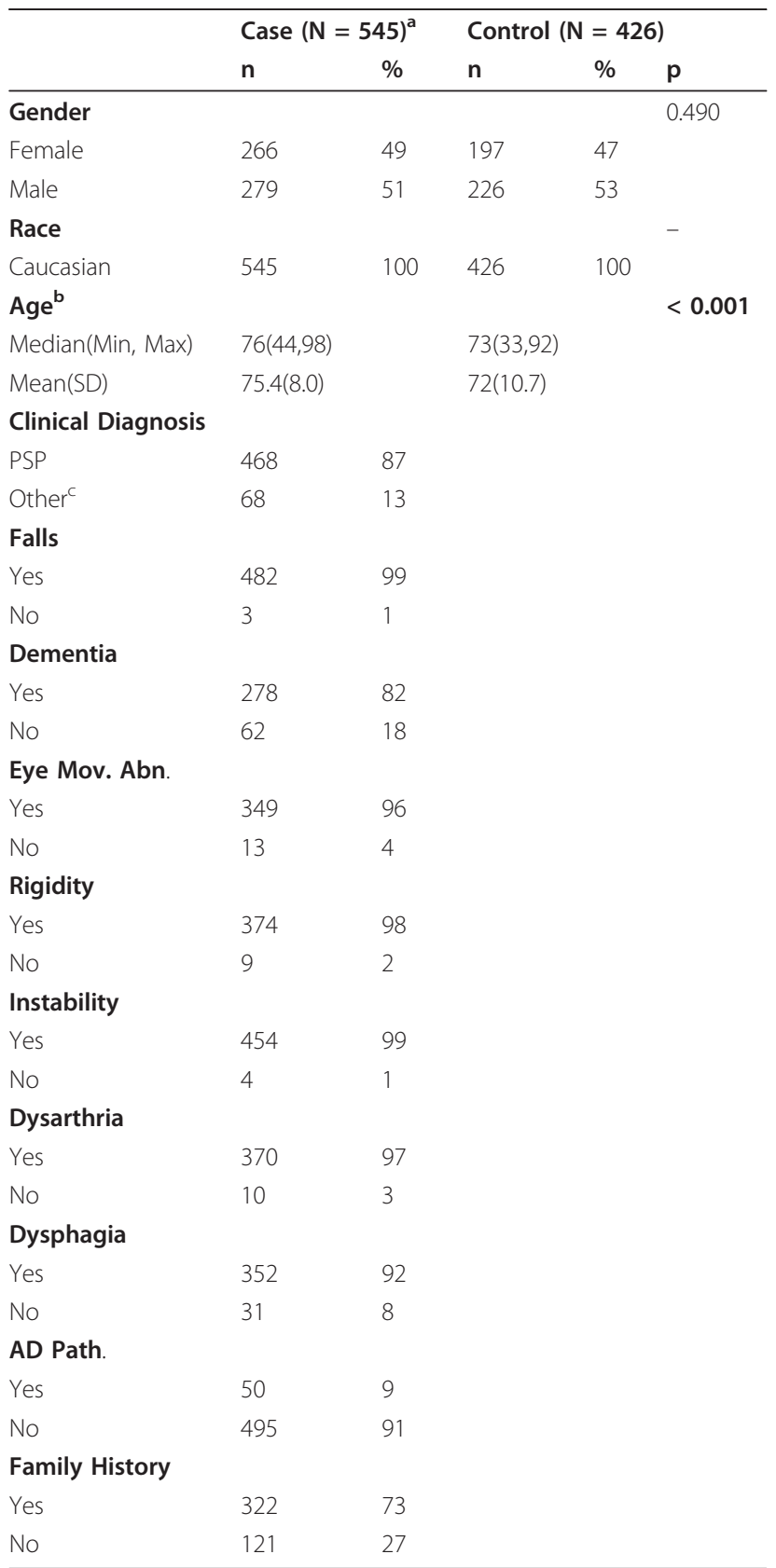

ans of cases for characteristics including and following "clinical diagnosis" may not total 545 as information for these variables was not available for every case.\% represent $\%$ of those with data. ${ }^{b}$ Age represents age at death for cases and age at blood draw for controls. 'Other clinical diagnoses included Alzheimer disease, Parkinson's disease, corticobasal degeneration, multiple system atrophy, Parkinson's disease with dementia, vascular dementia, progressive non-fluent aphasia and dementia. Abbreviations: $p=p$-value (chisquared), Eye Mov. Abn. = eye movement abnormalities, AD Path. $=$ presence of coexisting Alzheimer's pathology

\section{Data analysis}

Statistical analyses were performed using $\mathrm{R}$ software ( $\mathrm{R}$ Development Core Team 2009). Chi-squared, Fisher's exact, student $t$-test, or Wilcoxon rank sum analyses were used to test for differences in demographic variables between cases and controls. For each iPLEX SNP variable, the Cochran-Armitage and chi-squared tests were used to test additive, dominant, and recessive genetic models. In addition, logistic regression was used to test these same genetic models while adjusting for significant demographic variables (i.e. age). Logistic regression models were also used to determine whether specific NAT1 or NAT2 genotypes or NAT2 phenotypes were associated with PSP. NAT2 phenotypes may be accurately assigned according to genotype [22]; therefore, NAT2 analysis was initially restricted to phenotypic evaluation, which was followed by genotypic analysis. Overall significance of the associations was determined using the omnibus chi-squared test for the model. If the omnibus chi-squared test was not significant, then individual genotypes were not considered significant even if the associated $\mathrm{p}$-value $(\mathrm{p})$ was $<0.05$. Odds ratios $(\mathrm{OR})$, $95 \%$ confidence intervals $(\mathrm{CI})$ and p-values were determined for each variable. Associations with $\mathrm{p}<0.05$ were considered significant. Based on the outcome of the primary analysis, $t$-test or Wilcoxon rank sum test was applied to determine whether means/medians were different between NAT2 phenotypes for age at onset, age at death or disease duration in cases. NAT2 genotype, NAT1 genotype and iPLEX SNP associations were all tested independently each with either a large number of groups or a low number of tests; nevertheless, when pvalues were less than 0.05 , adjustments were made for multiple testing using the Holm correction [45]. NAT2 phenotype tests were modeled independently from SNP analyses. Furthermore, while multiple SNPs were determined to input the phenotypes, only two phenotypes were compared (i.e. rapid versus slow/intermediate), therefore no multiple testing correction was needed as previously described for testing the NAT2 phenotype association with colorectal cancer [46].

\section{Results}

On average, cases were older than controls at sample collection time (Table $1, \mathrm{p}<0.001$ ), with age at collection time for PSP cases being age at death. Trend analysis of the iPLEX SNPs showed no between-group differences in genotypes (Table 2), with the exception of rs1052553 (MAPT H1 OR $=4.35, \mathrm{CI}=3.08-6.25$, p < 0.001), which is a known association [47]. Each marker was confirmed to be in Hardy-Weinberg equilibrium in controls. Minor allele frequencies (MAFs) for rs numbers 1043424 and 705381 were higher in both our PSP and control populations compared to that reported for the general (Caucasian) population. For rs numbers 4880 and 1052553 only the PSP sample differed from the general population (Table 3 ). There were no between-group differences for NAT1 genotypes (Table 4). NAT2 slow and intermediate phenotypes did not 
Table 2 Case-control comparison of SNP genotypes

\begin{tabular}{|c|c|c|c|c|c|c|c|c|c|c|c|c|c|c|}
\hline \multirow[b]{2}{*}{$\begin{array}{c}\text { SNP rs marker (gene } \\
\text { name) }\end{array}$} & \multirow{2}{*}{$\begin{array}{c}\text { Total } \\
n \\
\text { Controls } \\
(\text { freq })^{\mathrm{a}}\end{array}$} & \multirow{2}{*}{$\begin{array}{c}\text { Total } \\
\mathrm{n} \\
\underset{\mathrm{a}}{\text { Cases (freq) }}\end{array}$} & \multicolumn{3}{|c|}{ n-controls } & \multicolumn{4}{|c|}{ n-cases } & \multirow[b]{2}{*}{$\mathrm{Cl}$} & \multirow[b]{2}{*}{ trend } & \multicolumn{2}{|l|}{$p$} & \multirow{2}{*}{$\begin{array}{c}q \\
\text { Holm }\end{array}$} \\
\hline & & & 0 & 1 & 2 & 0 & 1 & 2 & OR & & & recess. & dom. & \\
\hline rs1135840 & 395 & 500 & 133 & 183 & 79 & 145 & 240 & 115 & 1.14 & $0.94-1.37$ & 0.174 & 0.367 & 0.188 & 1 \\
\hline (CYP2D6) & 0.44 & 0.56 & 0.34 & 0.56 & 0.2 & 0.39 & 0.5 & 0.23 & & & & & & \\
\hline rs3738136 & 412 & 521 & 375 & 36 & 1 & 469 & 48 & 4 & 1.11 & $0.73-1.7$ & 0.625 & 0.338 & 0.78 & 1 \\
\hline (PINK-1) & 0.44 & 0.56 & 0.91 & 0.19 & 0 & 0.9 & 0.19 & 0.01 & & & & & & \\
\hline rs1043424 & 414 & 520 & 217 & 165 & 32 & 281 & 208 & 31 & 0.89 & $0.72-1.1$ & 0.27 & 0.19 & 0.478 & 1 \\
\hline (PINK-1) & 0.44 & 0.56 & 0.52 & 0.4 & 0.18 & 0.54 & 0.4 & 0.16 & & & & & & \\
\hline rs2234694 & 412 & 521 & 372 & 38 & 2 & 478 & 41 & 2 & 0.84 & $0.54-1.28$ & 0.411 & 0.813 & 0.408 & 1 \\
\hline (SOD1) & 0.44 & 0.56 & 0.9 & 0.19 & 0 & 0.92 & 0.18 & 0 & & & & & & \\
\hline rs4880 & 413 & 523 & 107 & 206 & 100 & 116 & 264 & 143 & 1.14 & $0.95-1.38$ & 0.157 & 0.22 & 0.279 & 1 \\
\hline (SOD2) & 0.44 & 0.56 & 0.36 & 0.5 & 0.24 & 0.22 & 0.5 & 0.37 & & & & & & \\
\hline rs662 & 414 & 521 & 211 & 160 & 43 & 256 & 217 & 48 & 1.03 & $0.85-1.26$ & 0.757 & 0.65 & 0.497 & 1 \\
\hline$(P O N 1)$ & 0.44 & 0.56 & 0.51 & 0.49 & 0.1 & 0.59 & 0.42 & 0.09 & & & & & & \\
\hline rs854560 & 412 & 521 & 181 & 176 & 55 & 213 & 242 & 66 & 1.02 & $0.84-1.23$ & 0.875 & 0.661 & 0.606 & 1 \\
\hline$(P O N 1)$ & 0.44 & 0.56 & 0.44 & 0.43 & 0.13 & 0.41 & 0.56 & 0.13 & & & & & & \\
\hline rs705381 & 409 & 523 & 231 & 148 & 30 & 293 & 201 & 29 & 0.98 & $0.79-1.21$ & 0.845 & 0.355 & 0.831 & 1 \\
\hline$(P O N 1)$ & 0.44 & 0.56 & 0.6 & 0.46 & 0.11 & 0.66 & 0.48 & 0.16 & & & & & & \\
\hline rs7493 & 413 & 523 & 237 & 148 & 28 & 315 & 181 & 27 & 0.9 & $0.73-1.12$ & 0.349 & 0.265 & 0.535 & 1 \\
\hline$(P O N 2)$ & 0.44 & 0.56 & 0.67 & 0.46 & 0.17 & 0.6 & 0.45 & 0.15 & & & & & & \\
\hline rs 12026 & 412 & 521 & 237 & 147 & 28 & 314 & 180 & 27 & 0.9 & $0.73-1.12$ & 0.364 & 0.267 & 0.558 & 1 \\
\hline (PON2) & 0.44 & 0.56 & 0.68 & 0.46 & 0.17 & 0.6 & 0.45 & 0.15 & & & & & & \\
\hline rs1052553 & 406 & 324 & 231 & 148 & 27 & 281 & 40 & 3 & 0.23 & $\begin{array}{l}0.16- \\
0.32\end{array}$ & $\begin{array}{c}< \\
0.001\end{array}$ & 0.001 & $\begin{array}{c}< \\
0.001\end{array}$ & $\begin{array}{c}< \\
0.001\end{array}$ \\
\hline (MAPT) & 0.56 & 0.44 & 0.67 & 0.46 & 0.17 & 0.97 & 0.12 & 0.01 & & & & & & \\
\hline
\end{tabular}

Logistic regression trend test comparing genotype differences between cases and controls, adjusted for age (age at death for cases, age at draw for controls). ${ }^{a}$ Frequency = number of samples in a particular variable category (i.e. "cases" or "0, 1, 2") divided by the total $n$ for that variable (i.e. "cases + controls" or " $0+1$ $+2 "$ ). "0" represents common allele homozygous genotype for SNP tested, $1=$ heterozygote, $2=$ minor allele homozygous. OR $=$ odds ratios for increase in the number of alleles (i.e. from 0 to 1 or 1 to 2 ); $\mathrm{Cl}=95 \%$ confidence intervals for ORs; $\mathrm{p}=\mathrm{p}$-values reported for trend test as well as for recessive (recess.) and dominant (dom.) models; $q$ = q-values for multiple testing adjustment using Holm's method.

differ between groups $(\mathrm{p}=0.96)$, thus these groups were combined and compared against the rapid phenotype for further analyses. Phenotypic analysis showed cases had a significantly higher proportion of NAT2 rapid acetylators $(\mathrm{OR}=1.82, \mathrm{CI}=1.05-3.28, \mathrm{p}=0.037)$ compared to intermediate and slow (Table 5). The omnibus chi-squared test for NAT2 genotypes was not significant (Table 6). Since NAT2 rapid phenotype was associated

Table 3 Allele Frequencies of SNPs vs. General Population

\begin{tabular}{|c|c|c|c|c|c|c|c|c|c|c|}
\hline \multirow[b]{2}{*}{ Marker } & \multirow{2}{*}{$\begin{array}{l}\text { Allele } \\
\text { Mn/Mj }\end{array}$} & \multirow{2}{*}{$\begin{array}{l}\text { MAF } \\
\text { pop }^{a}\end{array}$} & \multicolumn{3}{|c|}{ Controls } & \multirow{2}{*}{$\begin{array}{c}q \\
\text { Holm }\end{array}$} & \multicolumn{2}{|c|}{ Cases } & \multirow[b]{2}{*}{$p$} & \multirow[b]{2}{*}{$q$} \\
\hline & & & MAF & $\mathrm{Cl}$ & $p$ & & MAF & $\mathrm{Cl}$ & & \\
\hline rs1135840 & $\mathrm{G} / \mathrm{C}$ & 0.43 & 0.432 & $0.40-0.47$ & 0.954 & 1 & 0.47 & $0.44-0.50$ & 0.012 & 0.081 \\
\hline rs3738136 & $\mathrm{A} / \mathrm{G}$ & 0.06 & 0.046 & $0.03-0.06$ & 0.109 & 0.543 & 0.054 & $0.04-0.07$ & 0.432 & 1.000 \\
\hline rs1043424 & $C / G$ & 0.34 & 0.277 & $0.25-0.31$ & $<0.001$ & 0.001 & 0.26 & $0.23-0.29$ & $<0.001$ & $<0.001$ \\
\hline rs2234694 & $C / A$ & 0.042 & 0.051 & $0.04-0.07$ & 0.231 & 0.925 & 0.043 & $0.03-0.06$ & 0.91 & 1.000 \\
\hline rs4880 & $\mathrm{C} / \mathrm{T}$ & 0.45 & 0.492 & $0.46-0.53$ & 0.018 & 0.145 & 0.526 & $0.50-0.56$ & $<0.001$ & $<0.001$ \\
\hline rs662 & $\mathrm{G} / \mathrm{A}$ & 0.33 & 0.297 & $0.27-0.33$ & 0.048 & 0.337 & 0.3 & $0.27-0.33$ & 0.046 & 0.273 \\
\hline rs854560 & $\mathrm{T} / \mathrm{A}$ & 0.38 & 0.347 & $0.31-0.38$ & 0.056 & 0.337 & 0.359 & $0.33-0.39$ & 0.171 & 0.854 \\
\hline rs705381 & $\mathrm{T} / \mathrm{C}$ & 0.18 & 0.254 & $0.23-0.29$ & $<0.001$ & $<0.001$ & 0.248 & $0.22-0.28$ & $<0.001$ & $<0.001$ \\
\hline rs7493 & $\mathrm{G} / \mathrm{C}$ & 0.24 & 0.247 & $0.22-0.28$ & 0.668 & 1 & 0.225 & $0.20-0.25$ & 0.261 & 1.000 \\
\hline rs12026 & $\mathrm{G} / \mathrm{C}$ & 0.24 & 0.246 & $0.22-0.28$ & 0.699 & 1 & 0.225 & $0.20-0.25$ & 0.258 & 1.000 \\
\hline rs1052553 & $G / A^{b}$ & 0.21 & 0.249 & $0.22-0.28$ & 0.008 & 0.068 & 0.071 & $0.05-0.09$ & $<0.001$ & $<0.001$ \\
\hline
\end{tabular}

MAFs of studied population (control/case) compared with the general population (MAF pop) using test of proportions. ${ }^{\mathrm{a}}$ Minor allele frequencies listed on NCBI from CEU data (CEU = Utah residents with north and western European ancestry). ${ }^{b}$ Note $\mathrm{G}=\mathrm{H} 2, \mathrm{~A}=\mathrm{H} 1$. Mn/Mj $-\mathrm{Minor}$ Allele/Major Allele; MAF = Minor Allele Frequency; $\mathrm{Cl}=95 \%$ confidence intervals for determined MAF for noted population (i.e. control or case); $p=p$-value (Chi-squared); $q=q$-values for multiple testing adjustment using Holm's method. 
Table 4 Case-control comparison of NAT1 genotypes

\begin{tabular}{|c|c|c|c|c|c|c|c|}
\hline \multirow[b]{2}{*}{ NAT1 Genotype } & \multicolumn{2}{|c|}{ Controls( $\mathrm{N}=426)$} & \multicolumn{2}{|c|}{ Cases $(\mathrm{N}=545)$} & \multirow[b]{2}{*}{ OR } & \multirow[b]{2}{*}{$\mathrm{Cl}$} & \multirow[b]{2}{*}{$\mathrm{p}$} \\
\hline & $\mathrm{n}$ & $\%$ & $\mathbf{n}$ & $\%$ & & & \\
\hline$N A T 1 * 4 / * 4$ & 211 & 50.8 & 268 & 49.7 & 1 & & \\
\hline NAT1 ${ }^{*} 10 /{ }^{*} 11 A$ & 4 & 1.0 & 5 & 0.9 & 1.03 & $0.26-4.35$ & 0.967 \\
\hline$N A T 1 * 10 /{ }^{*} 10$ & 14 & 3.4 & 22 & 4.1 & 1.22 & $0.61-2.52$ & 0.583 \\
\hline$N A T 1^{*} 4 /{ }^{*} 3$ & 13 & 3.1 & 23 & 4.3 & 1.50 & $0.74-3.14$ & 0.271 \\
\hline NAT1 ${ }^{*} 4 /{ }^{*} 14 A$ or ${ }^{*} 10 /{ }^{*} 14 B$ & 13 & 3.1 & 19 & 3.5 & 1.25 & $0.60-2.66$ & 0.552 \\
\hline NAT1*10/*14A & 4 & 1.0 & 6 & 1.1 & 1.12 & $0.31-4.45$ & 0.863 \\
\hline NAT1* $4 / * 10$ & 138 & 33.3 & 165 & 30.6 & 0.94 & $0.70-1.26$ & 0.677 \\
\hline $\mathrm{NAT1}^{*} 4 /{ }^{*} 11 \mathrm{~A}$ or ${ }^{*} 3 /{ }^{*} 11 B$ & 13 & 3.1 & 21 & 3.9 & 1.21 & $0.59-2.55$ & 0.607 \\
\hline NAT1*10/*15 & 0 & 0.0 & 1 & 0.2 & - & - & - \\
\hline NAT1* $11 A^{*} 14 A$ & 0 & 0.0 & 1 & 0.2 & - & - & - \\
\hline NAT1*3/*10 & 2 & 0.5 & 4 & 0.7 & 1.65 & $0.32-12.10$ & 0.567 \\
\hline$N A T 1 * 3 /{ }^{*} 14 A$ & 0 & 0.0 & 1 & 0.2 & - & - & - \\
\hline$N A T 1 * 4 /{ }^{*} 11 B$ & 0 & 0.0 & 1 & 0.2 & - & - & - \\
\hline NAT1*4/*15 & 3 & 0.7 & 2 & 0.4 & 0.37 & $0.05-2.39$ & 0.298 \\
\hline Missing & 11 & & 6 & & & & \\
\hline
\end{tabular}

Logistic regression analysis of individual NAT1 genotypes, adjusted for age. NAT1*4/*4 used as reference. Overall chi-squared $\mathrm{p}=0.99$ (likelihood ratio test). Genotypes with 10 or less counts in either group (case or control) were not included in overall test of significance. OR $=$ odds ratio, $\mathrm{Cl}=95 \%$ confidence intervals for ORs, $p=p$-value

with PSP, rank sum analyses were used to determine whether NAT2 acetylation status predicted either age at onset or disease duration. NAT2 phenotype was not associated with age at onset or age at death. For disease duration the overall test was also not significant; however, individual pairwise comparisons for disease duration using a $t$-test (unequal variances, Table 7) corroborated results for association of NAT2 rapid phenotype with disease (Table 5). For example, mean disease duration was shorter for rapid NAT2 phenotype (6.6 yrs.) compared to slow (7.5 yrs. $\mathrm{p}=0.025)$.

\section{Discussion}

Our primary analysis revealed that none of the iPLEX SNPs was proportionally different between cases and controls except for MAPT rs1052553, which is a known association. On the other hand, significant differences were detected when comparing MAFs of cases with reported MAFs for the general population. There were no differences in NAT1 or NAT2 genotypes between cases and controls. NAT2 rapid acetylator phenotype was more frequent in PSP cases than controls while intermediate and slow acetylator phenotypes were less frequent in cases.

Although trend analysis did not show differences between cases and controls for the iPLEX SNPs (i.e. except for rs1052553), cases did differ from the general population (CEU) in some MAFs. Of particular interest is SOD2 rs4880, which differed from the general population in cases, but not controls. Though not conclusive, this suggests a possible association of rs4880 with PSP. The MAPT H1 allele is known to be associated with PSP; however, it is the major allele. Consistent with previous studies, we found that MAPT genotype and MAFs differed between PSP cases, with the $H 1$ allele conferring risk $[6,44]$. Furthermore, MAF comparisons indicate the $H 2$ allele is protective, as it had a lower frequency in our cases compared to the general population (Table 3). Our results also suggest that NAT2 rapid acetylator status might increase risk for developing PSP. This is consistent with NAT2-catalyzed toxicant activation (perhaps via $\mathrm{O}$-acetylation). Therefore, a higher rate of acetylation

Table 5 Comparisons Between NAT2 Phenotypes

\begin{tabular}{|c|c|c|c|c|c|c|c|c|}
\hline \multirow[b]{2}{*}{ NAT2 Phenotype } & \multicolumn{2}{|c|}{ Controls $(\mathrm{N}=426)$} & \multicolumn{2}{|c|}{ Cases $(\mathrm{N}=545)$} & \multirow[b]{2}{*}{ OR } & \multirow[b]{2}{*}{$\mathrm{Cl}$} & \multirow[b]{2}{*}{$\mathrm{p}$} & \multirow[b]{2}{*}{$q$} \\
\hline & $\mathrm{n}$ & $\%$ & $\mathrm{n}$ & $\%$ & & & & \\
\hline Slow & 241 & 56.6 & 299 & 54.9 & 1 & - & - & - \\
\hline Intermediate & 161 & 37.8 & 198 & 36.4 & 0.993 & $0.76-1.31$ & 0.959 & 0.959 \\
\hline Rapid & 19 & 4.5 & 42 & 7.7 & 1.82 & $1.04-3.30$ & $0.042 \mathrm{a}$ & 0.084 \\
\hline
\end{tabular}

Logistic regression analysis of individual NAT2 phenotypes, adjusted for age OR = odds ratio, $\mathrm{Cl}=95 \%$ confidence intervals for ORs, $\mathrm{p}=\mathrm{p}$-value, $\mathrm{q}=\mathrm{q}$-values for multiple testing adjustment using Holm's method. ${ }^{a}$ When intermediate and slow phenotypes are combined (due to $p=0.96$ ) and used as reference, the $p$-value for rapid is 0.037 , and no multiple testing correction is needed since it is a single hypothesis 
Table 6 Case-control comparison of NAT2 genotypes

\begin{tabular}{|c|c|c|c|c|c|c|c|c|}
\hline \multirow[b]{2}{*}{ NAT2 Genotype (phenotype) } & \multicolumn{2}{|c|}{ Controls $(\mathrm{N}=426)$} & \multicolumn{2}{|c|}{ Cases $(\mathrm{N}=545)$} & \multirow[b]{2}{*}{ OR } & \multirow[b]{2}{*}{$\mathrm{Cl}$} & \multirow[b]{2}{*}{$\mathbf{p}$} & \multirow[b]{2}{*}{$q$} \\
\hline & $\mathrm{n}$ & $\%$ & n & $\%$ & & & & \\
\hline $\mathrm{NAT2}^{*} 4{ }^{*} 4$ (rapid) & 19 & 4.5 & 42 & 7.7 & 1 & & & \\
\hline NAT2*4/*5(intermediate) & 108 & 25.4 & 116 & 21.3 & 0.49 & $0.26-0.88$ & 0.021 & 0.168 \\
\hline NAT2*4/*6 (intermediate) & 49 & 11.5 & 69 & 12.7 & 0.6 & $0.30-1.16$ & 0.133 & 0.532 \\
\hline NAT2*4/*7 (intermediate) & 4 & 0.9 & 13 & 2.4 & 1.43 & $0.43-5.65$ & 0.576 & 1 \\
\hline NAT2*5/*6 (slow) & 106 & 24.9 & 130 & 23.9 & 0.55 & $0.29-0.99$ & 0.053 & 0.318 \\
\hline NAT2*5/*7 (slow) & 5 & 1.2 & 10 & 1.8 & 0.86 & $0.26-3.10$ & 0.809 & 1 \\
\hline$N A T 2 * 6 / * 6$ (slow) & 42 & 9.9 & 47 & 8.6 & 0.46 & $0.23-0.92$ & 0.029 & 0.203 \\
\hline NAT2*6/*7 (slow) & 5 & 1.2 & 7 & 1.3 & 0.56 & $0.15-2.21$ & 0.394 & 1 \\
\hline NAT2*5/*5 (slow) & 82 & 19.2 & 104 & 19.1 & 0.58 & $0.31-1.07$ & 0.086 & 0.430 \\
\hline NAT2*5/*14 (slow) & 1 & 0.2 & 0 & 0 & - & - & - & \\
\hline NAT2*6/*14 (slow) & 0 & 0 & 1 & 0.2 & - & - & - & \\
\hline Missing & 5 & & 6 & & - & - & - & \\
\hline
\end{tabular}

would result in a higher concentration of toxic metabolite in the system. NAT2 catalyzes the O-acetylation of $\mathrm{N}$-arylhydroxylamines resulting in bioactivation [48].

This is an observational study, therefore more emphasis should be placed on the estimated odds ratio and precision of the confidence intervals rather than on $\mathrm{p}$ values [49]. Nevertheless, these trends must be confirmed by additional studies. Our results did not provide statistical evidence for an effect of NAT2 phenotype on onset age, age at death or disease duration. In accord with our finding that NAT2 rapid phenotype is more frequent in cases than controls, pairwise comparisons did show a trend supporting a potential link between

Table 7 Survival of PSP cases by NAT2 phenotype

\begin{tabular}{llll}
\hline NAT2 Phenotype & $\begin{array}{l}\text { Median(Min, } \\
\text { Max) }\end{array}$ & $\begin{array}{l}\text { Mean } \\
\text { (SD) }\end{array}$ & p-values \\
\hline Age at Onset & & & \\
Rapid & $68.5(51,85)$ & $68.5(8.5)$ & $>0.05$ \\
Intermediate & $68(41,89)$ & $68.1(8.6)$ & $>0.05$ \\
Slow & $68(47,90)$ & $67.9(8.1)$ & - \\
Age at Death & & & \\
Rapid & $75.5(58,89)$ & $75.3(7.9)$ & $>0.05$ \\
Intermediate & $76(44,98)$ & $75.3(8.3)$ & $>0.05$ \\
Slow & $76(53,95)$ & $75.4(7.9)$ & - \\
Disease Duration & & & \\
(yrs.) & & & \\
Rapid & & $6.6(2.2)$ & $0.025,0.078$, \\
& $6(2,12)$ & $7.4(3.6)$ & 0.028 \\
Intermediate & $7(2,31)$ & $7.5(3.3)$ & - \\
Slow & $7(0,27)$ &
\end{tabular}

Pairwise comparisons of age at onset, age at death, and disease duration by NAT2 phenotype ( $t$-test with unequal variances). ${ }^{a} p$-values $=$ rapid vs. slow, rapid vs. intermediate, rapid vs. slow + intermediate, respectively. ${ }^{b} \mathrm{p}$-value $=$ slow vs. intermediate. Overall $\mathrm{p}$-values from Wilcoxon rank sum tests were all $>0.1$ rapid phenotype and shorter disease duration (Table 7). It is important to note that this particular analysis may have been underpowered for detecting differences in the outcome parameters since the lack of disease onset and duration information for many cases substantially decreased the sample size.

Our findings are noteworthy as NAT2*4, which confers the rapid phenotype, was designated originally as the "wild-type" allele http://louisville.edu/medschool/ pharmacology/nat/ since it is common among many ethnic groups other than Europeans or Caucasians [29]. Although the frequency of NAT2*4 is not as common among Caucasians (which is the group analyzed in our study), this association may still be similar to the MAPT $H 1$ haplotype association with PSP (i.e. MAPT H1 is associated with increased PSP risk, but is also very common in the general population with a frequency of 0.78 ) [6]. Therefore, even though our results suggest the rapid acetylator phenotype increases risk for PSP, this is only one of potentially numerous factors that converge to determine individual risk for disease. On the other hand, our finding is contrary to recent findings that NAT2 rapid acetylator genes enhance the protective effect of smoking in PD (De Palma et al. 2010) and reports suggesting that the NAT2 slow acetylator phenotype increases risk for PD [50-52]. PSP is a tauopathy and PD is a synucleinopathy, thus, these are two distinct diseases that may have distinct pathogenic mechanisms and risk factors [53]. There are varying reports of NAT2 polymorphisms associating with $\mathrm{PD}$, PSP, and AD. While many suggest that slow alleles or phenotypes increase disease risk [31,32,50-52], others indicate increased risk with rapid or intermediate conferring genotypes and protection by slow alleles or genotypes $[13,54]$. Still others suggest there are no links between 
these diseases and NAT polymorphisms [18,30,33,55,56]. In view of these conflicting reports on the role of NAT genetic polymorphisms in neurodegeneration together with our results, additional studies are needed to determine whether NAT alleles or genotypes conferring rapid acetylation increase risk for neurodegenerative diseases or if the slow alleles/genotypes are protective or vice versa.

\section{Conclusions}

The control series we used was more geographically confined than our PSP population and the CEU population from which the general population MAFs were derived. Interestingly, for some of the MAFs our control population differed from the general population. This could explain why our genotype comparisons between cases and controls were not significant. Therefore, MAF comparisons between our PSP sample and the general/CEU population augment our case-control analyses. The main strength of this study was the large sample of pathologically well-characterized PSP cases from a single center. On the other hand, the clinical information was not collected in a systematic or standardized manner and controls were clinical, not pathological controls. Considering that PSP is a relatively rare disease, a still larger sample size may be necessary to detect smaller, yet biologically significant differences and investigate interaction effects. Likewise, as 514 of the PSP cases analyzed here were also included in the GWAS, this finding should be confirmed in an independent cohort. Although these findings need to be replicated, this data provides useful information to guide future genetic studies on PSP as it indicates that NAT2 rapid acetylator status should be considered as a potential risk factor for PSP in studies investigating gene-gene and geneenvironment interactions. Furthermore, our results are consistent with the recent genome-wide association study (GWAS) on PSP that did not find any associations with SNPs rs1043424, rs662, rs7493 or any individual NAT2 SNPs [44]. The NAT2rs numbers tested here and included in the recent GWAS on PSP are rs1801280, rs1799930, rs1799931, rs1799929, and rs1041983 [44]. Though we did not find an association with any individual NAT2 SNPs, when we used the SNPs to input NAT2 phenotype we observed a significant association between imputed rapid NAT2 acetylator phenotype and PSP. This result is important since this method of testing NAT2 phenotype association with disease has been shown to be more useful than looking at individual SNPs $[57,58]$. Thus, our study is quite different from the GWAS, and with respect to NAT2, much more powerful in terms of biological plausibility. Additionally, this study reveals the odds ratios and confidence intervals for a number of biologically relevant SNPs that have not been previously investigated in association studies on PSP. Our results provide support for the multiple-hit hypothesis and demonstrate the multifaceted nature of identifying risk factors for neurodegenerative diseases such as PSP.

\section{Acknowledgements}

We thank the patients and their families as well as those individuals who donated samples to the bio-repository. Thanks to research coordinators Jennifer Lash, Jill Searcy, and Audrey Strongosky from Mayo Clinic Jacksonville for assistance with sample collection and to Mark Doll, Alexandra Soto-Ortolaza and Jennifer Adamson for technical assistance. The Society for Progressive Supranuclear Palsy brain bank is supported by a grant to Dr. Dickson from CurePSP, Inc. This research was supported by the University of Louisville Center for Environmental Genomics and Integrative Biology award number P30ES014443. Dr. Litvan is partially supported by $\mathrm{NIH}$ R01 PAS-03-092, National Parkinson Foundation, Parkinson Support Center of Kentuckiana. Dr. Litvan is founder and CEO of the Litvan Neurological Research Foundation, whose mission is to increase awareness, determine the cause/s and search for a cure for neurodegenerative disorders presenting with either parkinsonian or dementia symptoms (501c3). Dr. Rai is supported by the Wendell Cherry Chair endowment for clinical trial research and the JG Brown Cancer Center. Dr. Hein was supported by NIH R01-CA034627. Dr. Wszolek is partially supported by the NIH 1RC2-NS070276, P01-NS057567, Mayo Clinic Florida (MCF) Research Committee CR programs (MCF $\# 90052030$ and MCF \#90052030). Dr. Uitti is partially supported by the NIH P01- NS057567, Mayo Clinic Florida (MCF) Research Committee CR programs (MCF \#90052030 and MCF \#90052030). Drs. Dickson, Uitti, Wszolek, Ross and Rademakers are supported by NIH P50-NS072187, NIH P50-NS072187-01S2, and NIH P50-AG16574.

\section{Author details}

${ }^{1}$ Department of Anatomical Sciences and Neurobiology, University of Louisville, Louisville, KY, USA. '2Department of Bioinformatics and Biostatistics, University of Louisville, Louisville, KY, USA. ${ }^{3}$ Department of Neuroscience, Mayo Clinic Jacksonville, Jacksonville, FL, USA. ${ }^{4}$ Department of Neurology, Mayo Clinic Jacksonville, Jacksonville, FL, USA. ${ }^{5}$ J.G. Brown Cancer Center, University of Louisville, Louisville, KY, USA. ${ }^{6}$ Department of Medical Genetics, Centre of Applied Neurogenetics, Brain Research Centre, University of British Columbia, Vancouver, British Columbia, Canada. ${ }^{7}$ Department of Pharmacology and Toxicology, University of Louisville, Louisville, KY, USA. ${ }^{8}$ Department of Neurology, University of Louisville, Louisville, KY, USA. ${ }^{9}$ Department of Neurosciences, University of California San Diego, La Jolla, CA, USA.

\section{Authors' contributions}

LFP participated in study conception and design, carried out NAT genotyping, assisted in data analysis and was primarily responsible for drafting the manuscript. ACC performed statistical analysis and assisted in data interpretation and manuscript preparation. OAR participated in study design and iPLEX genotyping and manuscript critique. RR helped with study design and DNA preparation. DWD, RJU and ZWK provided samples and were involved in manuscript review and critique. SNR assisted in statistical analysis and data interpretation. MJF participated in study design and manuscript critique. DWH participated in study design, data analysis, and manuscript critique. IL was responsible for study conception, design and manuscript review and critique.

\section{Competing interests}

The authors declare that they have no competing interests. This research was conducted in accordance with institutional review board approved procedures.

Received: 16 September 2011 Accepted: 17 March 2012

Published: 17 March 2012

\section{References}

1. Hauw JJ, Daniel SE, Dickson D, Horoupian DS, Jellinger K, Lantos PL, McKee A, Tabaton M, Litvan I: Preliminary NINDS neuropathologic criteria for Steele-Richardson-Olszewski syndrome (progressive supranuclear palsy). Neurology 1994, 44(11):2015-2019. 
2. Albers DS, Beal MF: Mitochondrial dysfunction in progressive supranuclear palsy. Neurochem/nt 2002, 40(6):559-564.

3. Stamelou M, Pilatus U, Reuss A, Magerkurth J, Eggert KM, Knake S, Ruberg M, Schade-Brittinger C, Oertel WH, Hoglinger GU: In vivo evidence for cerebral depletion in high-energy phosphates in progressive supranuclear palsy. J Cereb Blood Flow Metab 2009, 29(4):861-870.

4. Ishizawa K, Dickson DW: Microglial activation parallels system degeneration in progressive supranuclear palsy and corticobasal degeneration. J NeuropatholExpNeurol 2001, 60(6):647-657.

5. Bonifati V, Joosse M, Nicholl DJ, Vanacore N, Bennett P, Rizzu P, Fabbrini G Marconi $\mathrm{R}$, Colosimo $\mathrm{C}$, Locuratolo $\mathrm{N}$, et al: The tau gene in progressive supranuclear palsy: exclusion of mutations in coding exons and exon 10 splice sites, and identification of a new intronic variant of the diseaseassociated H1 haplotype in Italian cases. Neuroscilett 1999, 274(1):61-65.

6. Baker M, Litvan I, Houlden H, Adamson J, Dickson D, Perez-Tur J, Hardy J, Lynch T, Bigio E, Hutton M: Association of an extended haplotype in the tau gene with progressive supranuclear palsy. Hum Mol Genet 1999, 8(4):711-715.

7. Elbaz A, Ross OA, loannidis JP, Soto-Ortolaza Al, Moisan F, Aasly J, Annesi G, Bozi M, Brighina L, Chartier-Harlin MC, et al: Independent and joint effects of the MAPT and SNCA genes in Parkinson disease. Ann Neurol 2011, 69(5):778-792.

8. Dodson MW, Guo M: Pink1, Parkin, DJ-1 and mitochondrial dysfunction in Parkinson's disease. CurrOpinNeurobiol 2007, 17(3):331-337.

9. Kim Y, Park J, Kim S, Song S, Kwon SK, Lee SH, Kitada T, Kim JM, Chung J: PINK1 controls mitochondrial localization of Parkin through direct phosphorylation. BiochemBiophys Res Commun 2008, 377(3):975-980.

10. Fong CS, Cheng CW, Wu RM: Pesticides exposure and genetic polymorphism of paraoxonase in the susceptibility of Parkinson's disease. ActaNeurol Taiwan 2005, 14(2):55-60.

11. Mellick GD: CYP450, genetics and Parkinson's disease: gene $\times$ environment interactions hold the key. J Neural TransmSuppl 2006 70:159-165.

12. Costa C, Catania S, Silvari V: [Genotoxicity and activation of organophosphate and carbamate pesticides by cytochrome P450 2D6]. Giornaleitaliano di medicina del lavoroedergonomia 2003, 25(Suppl(3)):81-82.

13. Rocha L, Garcia C, de Mendonca A, Gil JP, Bishop DT, Lechner MC: Nacetyltransferase (NAT2) genotype and susceptibility of sporadic Alzheimer's disease. Pharmacogenetics 1999, 9(1):9-15.

14. Champy P, Hoglinger GU, Feger J, Gleye C, Hocquemiller R, Laurens A, Guerineau V, Laprevote O, Medja F, Lombes A, et al: Annonacin, a lipophilic inhibitor of mitochondrial complex I, induces nigral and striatal neurodegeneration in rats: possible relevance for atypical parkinsonism in Guadeloupe. J Neurochem 2004, 88(1):63-69.

15. Lannuzel A, Hoglinger GU, Verhaeghe S, Gire L, Belson S, EscobarKhondiker M, Poullain P, Oertel WH, Hirsch EC, Dubois B, et al: Atypical parkinsonism in Guadeloupe: a common risk factor for two closely related phenotypes? Brain 2007, 130(Pt 3):816-827.

16. Liang TW, Balcer LJ, Solomon D, Messe SR, Galetta SL: Supranuclear gaze palsy and opsoclonus after Diazinon poisoning. I NeurolNeurosurg Psychiatry 2003, 74(5):677-679.

17. Chapuis J, Boscher M, Bensemain F, Cottel D, Amouyel P, Lambert JC: Association study of the paraoxonase 1 gene with the risk of developing Alzheimer's disease. Neurobiol Aging 2007.

18. Nicholl DJ, Bennett P, Hiller L, Bonifati V, Vanacore N, Fabbrini G, Marconi R, Colosimo C, Lamberti P, Stocchi F, et al: A study of five candidate genes in Parkinson's disease and related neurodegenerative disorders. European Study Group on Atypical Parkinsonism. Neurology 1999, 53(7):1415-1421.

19. Benmoyal-Segal L, Vander T, Shifman S, Bryk B, Ebstein RP, Marcus EL, Stessman J, Darvasi A, Herishanu Y, Friedman A, et al: Acetylcholinesterase/ paraoxonase interactions increase the risk of insecticide-induced Parkinson's disease. FASEB J 2005, 19(3):452-454.

20. Elbaz A, Levecque C, Clavel J, Vidal JS, Richard F, Amouyel P, Alperovitch A, Chartier-Harlin MC, Tzourio C: CYP2D6 polymorphism, pesticide exposure, and Parkinson's disease. Ann Neurol 2004, 55(3):430-434

21. Jaarsma D, Haasdijk ED, Grashorn JA, Hawkins R, van Duijn W, Verspaget HW, London J, Holstege JC: Human Cu/Zn superoxide dismutase (SOD1) overexpression in mice causes mitochondrial vacuolization, axonal degeneration, and premature motoneuron death and accelerates motoneuron disease in mice expressing a familial amyotrophic lateral sclerosis mutant SOD1. Neurobiol Dis 2000, 7(6 Pt B):623-643.

22. Hein DW: $\mathrm{N}$-acetyltransferase 2 genetic polymorphism: effects of carcinogen and haplotype on urinary bladder cancer risk. Oncogene 2006, 25(11):1649-1658

23. McCann SJ, Pond SM, James KM, LeCouteur DG: The association between polymorphisms in the cytochrome P-450 2D6 gene and Parkinson's disease: a case-control study and meta-analysis. J NeurolSci 1997, 153(1):50-53.

24. Singh M, Khanna VK, Shukla R, Parmar D: Association of polymorphism in cytochrome P450 2D6 and N-acetyltransferase-2 with Parkinson's disease. Dis Markers 2010, 28(2):87-93.

25. Kelada SN, Costa-Mallen P, Checkoway H, Viernes HA, Farin FM, SmithWeller T, Franklin GM, Costa LG, Longstreth WT Jr, Furlong CE, et al: Paraoxonase 1 promoter and coding region polymorphisms in Parkinson's disease. J NeurolNeurosurg Psychiatry 2003, 74(4):546-547.

26. Carmine A, Buervenich $S$, Sydow O, Anvret M, Olson L: Further evidence for an association of the paraoxonase 1 (PON1) Met-54 allele with Parkinson's disease. MovDisord 2002, 17(4):764-766.

27. Duric G, Svetel M, Nikolaevic SI, Dragadevic N, Gavrilovic J, Kostic VS: Polymorphisms in the genes of cytochrome oxidase P450 2D6 (CYP2D6), paraoxonase 1 (PON1) and apolipoprotein E (APOE) as risk factors for Parkinson's disease. Vojnosanit Pregl 2007, 64(1):25-30.

28. Erlich PM, Lunetta KL, Cupples LA, Huyck M, Green RC, Baldwin CT, Farrer LA: Polymorphisms in the PON gene cluster are associated with Alzheimer disease. Hum Mol Genet 2006, 15(1):77-85.

29. Boukouvala S, Fakis $\mathrm{G}$ : Arylamine $\mathrm{N}$-acetyltransferases: what we learn from genes and genomes. Drug metabolism reviews 2005, 37(3):511-564.

30. Maraganore DM, Farrer MJ, Hardy JA, McDonnell SK, Schaid DJ, Rocca WA: Case-control study of debrisoquine 4-hydroxylase, $\mathrm{N}$-acetyltransferase 2, and apolipoprotein E gene polymorphisms in Parkinson's disease. MovDisord 2000, 15(4):714-719.

31. Chan DK, Lam MK, Wong R, Hung WT, Wilcken DE: Strong association between $\mathrm{N}$-acetyltransferase 2 genotype and PD in Hong Kong Chinese. Neurology 2003, 60(6):1002-1005.

32. Chaudhary S, Behari M, Dihana M, Swaminath PV, Govindappa ST, Jayaram S, Singh S, Muthane UB, Juyal RC: B KT: Association of N-acetyl transferase 2 gene polymorphism and slow acetylator phenotype with young onset and late onset Parkinson's disease among Indians. Pharmacogenet Genomics 2005, 15(10):731-735.

33. Borlak J, Reamon-Buettner SM: N-acetyltransferase 2 (NAT2) gene polymorphisms in Parkinson's disease. BMC Med Genet 2006, 7:30.

34. Punia S, Das M, Behari M, Dihana M, Govindappa ST, Muthane UB, Thelma BK, Juyal RC: Leads from xenobiotic metabolism genes for Parkinson's disease among north Indians. Pharmacogenet Genomics 2011, 21(12):790-797.

35. Jaarsma D, Haasdijk ED, Grashorn JA, Hawkins R, van Duijn W Verspaget HW, London J, Holstege JC: Human Cu/Zn superoxide dismutase (SOD1) overexpression in mice causes mitochondrial vacuolization, axonal degeneration, and premature motoneuron death and accelerates motoneuron disease in mice expressing a familial amyotrophic lateral sclerosis mutant SOD1. Neurobiology of disease 2000 7(6 Pt B):623-643.

36. Liu D, Bao F. Wen J, Liu J: Mutation of superoxide dismutase elevates reactive species: comparison of nitration and oxidation of proteins in different brain regions of transgenic mice with amyotrophic lateral sclerosis. Neuroscience 2007, 146(1):255-264.

37. Zimmerman MC, Oberley LW, Flanagan SW: Mutant SOD1-induced neuronal toxicity is mediated by increased mitochondrial superoxide levels. Journal of neurochemistry 2007, 102(3):609-618.

38. Naini A, Mehrazin M, Lu J, Gordon P, Mitsumoto H: Identification of a novel D109Y mutation in Cu/Zn superoxide dismutase (sod1) gene associated with amyotrophic lateral sclerosis. J NeurolSci 2007, 254(12):17-21.

39. Choi J, Rees HD, Weintraub ST, Levey Al, Chin LS, Li L: Oxidative modifications and aggregation of $\mathrm{Cu}, \mathrm{Zn}$-superoxide dismutase associated with Alzheimer and Parkinson diseases. The Journal of biological chemistry 2005, 280(12):11648-11655.

40. Josephs KA, Dickson DW: Diagnostic accuracy of progressive supranuclear palsy in the Society for Progressive Supranuclear Palsy brain bank. MovDisord 2003, 18(9):1018-1026. 
41. Doll MA, Hein DW: Comprehensive human NAT2 genotype method using single nucleotide polymorphism-specific polymerase chain reaction primers and fluorogenic probes. Anal Biochem 2001, 288(1):106-108.

42. Doll MA, Hein DW: Rapid genotype method to distinguish frequent and/ or functional polymorphisms in human $\mathrm{N}$-acetyltransferase-1. Anal Biochem 2002, 301(2):328-332.

43. Thomas RK, Baker AC, Debiasi RM, Winckler W, Laframboise T, Lin WM, Wang M, Feng W, Zander T, MacConaill L, et al: High-throughput oncogene mutation profiling in human cancer. Nat Genet 2007, 39(3):347-351.

44. Hoglinger GU, Melhem NM, Dickson DW, Sleiman PM, Wang LS, Klei L, Rademakers R, de Silva R, Litvan I, Riley DE, et al: Identification of common variants influencing risk of the tauopathy progressive supranuclear palsy. Nat Genet 2011, 43(7):699-705.

45. Holm S: A Simple Sequentially Refective Multiple Test Procedure. Scandinavian Journal of Statistics 1979, 6:65-70.

46. Le Marchand L, Hankin JH, Wilkens LR, Pierce LM, Franke A, Kolonel LN, Seifried A, Custer L, Chang W, Lum-Jones A, et al: Combined effects of well-done red meat, smoking, and rapid $\mathrm{N}$-acetyltransferase 2 and CYP1A2 phenotypes in increasing colorectal cancer risk. Cancer Epidemiol Biomarkers Prev 2001, 10(12):1259-1266.

47. Russ C, Powell JF, Zhao J, Baker M, Hutton M, Crawford F, Mullan M, Roks G, Cruts M, Lovestone S: The microtubule associated protein Tau gene and Alzheimer's disease- an association study and meta-analysis. Neuroscilett 2001, 314(1-2):92-96

48. Liu L, Von Vett A, Zhang N, Walters KJ, Wagner CR, Hanna PE: Arylamine Nacetyltransferases: characterization of the substrate specificities and molecular interactions of environmental arylamines with human NAT1 and NAT2. Chem Res Toxicol 2007, 20(9):1300-1308.

49. Anderson DR, Link WA, Johnson DH, Burnham KP: Suggestions for presenting the results of data analyses. Journal of Wildlife Management 2001, 65(3):373-378

50. De Palma G, Dick FD, Calzetti S, Scott NW, Prescott GJ, Osborne A, Haites N, Mozzoni P, Negrotti A, Scaglioni A, et al: A case-control study of Parkinson's disease and tobacco use: gene-tobacco interactions. MovDisord 25(7):912-919.

51. Bandmann O, Vaughan J, Holmans PA, Marsden CD, Wood NW: Toxins, genetics, and Parkinson's disease: the role of $\mathrm{N}$-acetyltransferase 2. AdvNeurol 1999, 80:199-204.

52. Grundmann M, Earl CD, Sautter J, Henze C, Oertel WH, Bandmann O: Slow $\mathrm{N}$-acetyltransferase 2 status leads to enhanced intrastriatal dopamine depletion in 6-hydroxydopamine-lesioned rats. ExpNeurol 2004, 187(1):199-202.

53. Wider C, Vilarino-Guell C, Jasinska-Myga B, Heckman MG, Soto-Ortolaza Al, Cobb SA, Aasly JO, Gibson JM, Lynch T, Uitti RJ, et al: Association of the MAPT locus with Parkinson's disease. Eur J Neurol 17(3):483-486.

54. Guo WC, Lin GF, Zha YL, Lou KJ, Ma QW, Shen JH: N-Acetyltransferase 2 gene polymorphism in a group of senile dementia patients in Shanghai suburb. ActaPharmacol Sin 2004, 25(9):1112-1117.

55. Johnson N, Bell P, Jonovska V, Budge M, Sim E: NAT gene polymorphisms and susceptibility to Alzheimer's disease: identification of a novel NAT1 allelic variant. BMC Med Genet 2004, 5:6.

56. Golab-Janowska M, Honczarenko K, Gawronska-Szklarz B, Potemkowski A: The role of NAT2 gene polymorphism in aetiology of the most frequent neurodegenerative diseases with dementia. Neurologia $i$ neurochirurgiapolska 2007, 41(5):388-394.

57. Hein DW, Doll MA: Accuracy of various human NAT2 SNP genotyping panels to infer rapid, intermediate and slow acetylator phenotypes. Pharmacogenomics 2012, 13(1):31-41.

58. Deitz AC, Rothman N, Rebbeck TR, Hayes RB, Chow WH, Zheng W, Hein DW, Garcia-Closas M: Impact of misclassification in genotypeexposure interaction studies: example of N-acetyltransferase 2 (NAT2), smoking, and bladder cancer. Cancer Epidemiol Biomarkers Prev 2004, 13(9):1543-1546.

\section{Pre-publication history}

The pre-publication history for this paper can be accessed here:

http://www.biomedcentral.com/1471-2350/13/16/prepub doi:10.1186/1471-2350-13-16

Cite this article as: Potts et al:: Polymorphic genes of detoxification and mitochondrial enzymes and risk for progressive supranuclear palsy: a case control study. BMC Medical Genetics 2012 13:16.

\section{Submit your next manuscript to BioMed Central and take full advantage of:}

- Convenient online submission

- Thorough peer review

- No space constraints or color figure charges

- Immediate publication on acceptance

- Inclusion in PubMed, CAS, Scopus and Google Scholar

- Research which is freely available for redistribution

Submit your manuscript at www.biomedcentral.com/submit
C Biomed Central 